Pierre COMTE

Danilo ENGELMANN

Peter BONSACK

\title{
Non-legislated emissions and PN of two passenger cars with gasoline-butanol blends
}

\begin{abstract}
Increasing the sustainability of individual transportation and replacing a part of fossil energy in traffic by renewable energy carriers are worldwide important objectives. Bioalcohols are generally recognized as one of very useful alternatives. The global share of bioethanol used for transportation is continuously increasing. Butanol, a four-carbon alcohol, is considered in the last years as an interesting alternative fuel, both for diesel and for gasoline application. Its advantages for engine operation are: good miscibility with gasoline and diesel fuels, higher calorific value than ethanol, lower hygroscopicity, lower corrosivity and possibility of replacing aviation fuels.

In the present work, the emissions of two gasoline vehicles - with older and with newer technology - were investigated in dynamic-, stationary and cold start operation.
\end{abstract}

Key words: alternative fuels, alcohols, nanoparticles, ammonia, cold start, emissions gasoline

\section{Introduction}

\subsection{Butanol and its effects on SI-engines}

Butanol $\left(\mathrm{CH}_{3}\left(\mathrm{CH}_{2}\right)_{3} \mathrm{OH}\right)$ has a four-carbon structure and is a higherchain alcohol than Ethanol, as the carbon atoms can either form a straight chain (n-butanol) or a branched structure (iso-butanol), thus resulting in different properties. Consequently, it exists as different isomers depending on the location of the hydroxyl group $(-\mathrm{OH})$ and carbon chain structure, with butanol production from biomass tending to yield mainly straight chain molecules. 1-butanol, better known as $n$-butanol (normal butanol), has a straight-chain structure with the hydroxyl group $(-\mathrm{OH})$ at the terminal carbon.

$\mathrm{N}$-butanol is of particular interest as a renewable biofuel as it is less hydrophilic, and possesses higher energy content, higher cetane number, higher viscosity, lower vapour pressure, higher flash point and higher miscibility than ethanol, making it more preferable than Ethanol for blending with diesel fuel. It is also easily miscible with gasoline and it has no corrosive, or destructing activity on plastics, or metals, like ethanol or methanol.

Several research works were performed with different butanol blends BuXX [1-9]. Generally, there are advantages of higher heat value (than ethanol). The oxygen content of butanol has similar ad-vantages, like with other alcohols: tendency of less $\mathrm{CO} \& \mathrm{HC}$, but possibility of increasing $\mathrm{NO}_{\mathrm{x}}$ (depending on engine parameters setting).

The good miscibility, lower hygroscopicity and lower corrosivity make butanol interesting alternative.

The trend of downsizing the SI-engines in the last years implies much higher specific torques and with it an aptitude of knocking and mega-knocking at high- and full load. The alcohols have a higher octane numbers (RON), are more resistant to knocking and are a welcomed solution for this new technology of engines [1].

A basic research of butanol blends Bu20 \& Bu100 was performed on mono-cylinder engines with optical access to the combustion chamber [2,3]. One of the engines was with GDI configuration. It was demonstrated, that the alco- hol blend improved the internal mixture preparation and reduced the carbonaceous compounds formation and soot.

Concerning the characteristics of combustion Bu100 was similar to gasoline. This research considered only little number of constant operating points.

Using $n$-butanol in an optical port fuel injection (PFI) SI engine slightly higher combustion rates and lower formation of particulates was found compared to gasoline [4, 5]. Similarly [6] reported that the duration of the early combustion stage and length of combustion in an SI engine were, compared to gasoline, shortened with increased nbutanol share, and slightly lower variability of indicated mean pressure (IMEP) was observed when running on neat n-butanol. Shorter early combustion stage, faster combustion and better combustion stability were also observed by other researchers [7, 8].

The alcohol blend fuels E85 \& Bu85 were tested on a vehicle with TWC in road application and with on-board measuring system for exhaust emissions [9]. It was stated for butanol, that it has no significant influence on $\mathrm{CO} \&$ $\mathrm{HC}$, but it increases strongly $\mathrm{NO}_{\mathrm{x}}$. Nevertheless, this is due to the limits of lambda regulation and as effect of it to the production of too many lean lambda excursions during the transients.

The warm operation with Bu85 was with no problems, the cold startability and emissions were not investigated.

\subsection{Non-legislated emissions of gasoline cars}

The most important non-legislated emission components in present discussions are: the nanoparticles (NP), ammonia $\left(\mathrm{NH}_{3}\right)$, nitrous oxide $\left(\mathrm{N}_{2} \mathrm{O}\right)$, formaldehyde ( $\mathrm{HCHO})$ and acetaldehyde $(\mathrm{MeCHO})$.

The nanoparticles (NP) became an important research topic, since the first introduction of legal nanoparticle counts limits (Euro 5b) for DI SI passenger cars in EU beginning of 2013. In this situation, the NP and especially the metal oxides emissions from additive packages of lube oils and fuels, be-come an important topic for all kinds of engines. Lube oil contributes to the NP-emission especially 
at cold start [10-12]. These new aspects have to be investigated with Ethanol blend fuels Exx.

Further gaseous substances, which may be present under certain conditions in very low concentrations in the exhaust gases are considered to be potential candidates for future legal limitation. These non-legislated emission components are: ammonia $\left(\mathrm{NH}_{3}\right)$, nitrogen dioxide $\left(\mathrm{NO}_{2}\right)$, nitrous oxide $\left(\mathrm{N}_{2} \mathrm{O}\right)$, formaldehyde ( $\mathrm{HCHO})$ and acetaldehyde $(\mathrm{MeCHO})$ - all of them quite easy to be measured and indicated with FTIR.

Production of ammonia $\left(\mathrm{NH}_{3}\right)$ in the exhaust of gasoline cars with TWC was demonstrated in [13] and [14] - this especially at transient operation with rich excursions of lambda. The other components were little investigated in connection with E85-operation. From the research of the authors can be stated, that with a correctly working TWC (at warm operation) there are usually no measurable concentrations of $\mathrm{NO}_{2}$ and $\mathrm{N}_{2} \mathrm{O}$ and the $\mathrm{HCHO}$ - values show a noise below 1 ppm [15]. The components $\mathrm{HCHO}$ and $\mathrm{MeCHO}$ are supposed to produce a peak at cold start, but are little investigated and presented in the literature.

The presented tests were performed in the IC-Engines Laboratory of the University of Applied Sciences, Biel, CH within the framework of project GasBut (gasoline + butanol).

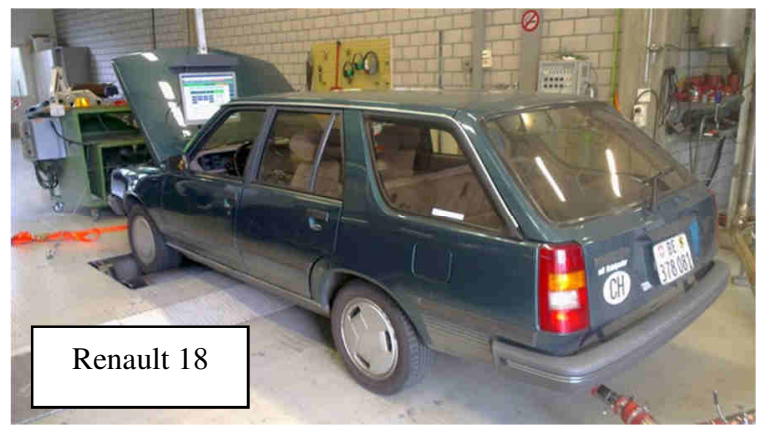

This research was conducted on two cars: an older one, with MPI \& $\lambda=1$ concept and a newer one (Euro 5), with GDI, $\lambda=1$ concept and flex fuel aptitude.

The test vehicles were driven at WLTC cold \& warm, as well as at a steady state cycle (SSC). The measurements of legislated and non-legislated emissions (NP \& FTIR) were attached.

Special attempts of cold starts were conducted and compared with the equivalent results with $\mathrm{Bu} 0$ \& Exx. The tests were performed with $\mathrm{Bu} 0, \mathrm{~B} 15$ and $\mathrm{Bu} 30$.

This research enabled a complete insight in the nonlegislated emissions at cold start and in repetitive transient operation with quite different state of the gasoline cars.

\section{Test vehicles, fuels and lubricants}

The tests on gasoline vehicles were performed: with a Renault 18 Break (SI, MPI, TWC), which represents an older technology in this project and with a flex fuel vehicle (FFV) Volvo V60 (GDI, Euro 5), which represents a newer technology. These vehicles were operated with gasoline, in original condition (TWC) and with two butanol blend fuels Bu15 and Bu30. The vehicles are presented in Fig. 1 and Tab. 1.

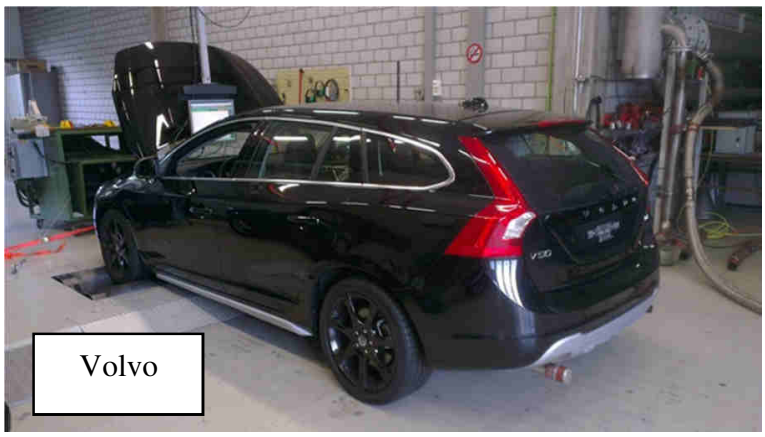

Fig. 1. Gasoline vehicles for research of emissions

Table 1. Data of tested vehicles

\begin{tabular}{|l|c|c|}
\hline Vehicle & Renault 18 Break & Volvo V60 T4F \\
\hline Engine code & J7T-718 & B4164T2 \\
\hline $\begin{array}{l}\text { Number and } \\
\text { arrangement of } \\
\text { cylinders }\end{array}$ & 4 / in line & 4 / in line \\
\hline $\begin{array}{l}\text { Displacement } \\
\text { cm3 }\end{array}$ & 2164 & 1596 \\
\hline Power kW & 74 @ 5000 rpm & 132 @ 5700 rpm \\
\hline Torque Nm & 162 @ 2000 rpm & 240 @ 1600 rpm \\
\hline Injection type & MPI & DI \\
\hline Curb weight kg & 1110 & 1554 \\
\hline $\begin{array}{l}\text { Gross vehicle } \\
\text { weight kg }\end{array}$ & 1585 & 2110 \\
\hline Drive wheel & Front-wheel drive & Front-wheel drive \\
\hline Gearbox & m5 & a6 \\
\hline $\begin{array}{l}\text { First registra- } \\
\text { tion }\end{array}$ & 01.04 .1985 & 27.01 .2012 \\
\hline Exhaust & EURO 0 & EURO 5a \\
\hline VIN & VF1135B00F0000505 & YV1FW075BC1043598 \\
\hline Vehicle & Renault 18 Break & Volvo V60 \\
\hline
\end{tabular}

\subsection{Fuels}

The gasoline used was from the Swiss market, RON 95, according to SN EN228; n-butanol was purchased from Thommen-Furler AG. As blend fuels were used: Bu15 and Bu30 (15\% vol. and 30\% vol. butanol).
Table 2. Fuel properties of the test fuels

\begin{tabular}{|l|c|c|c|}
\hline Specification & & RON 95 & n-butanol \\
\hline Other name & $\begin{array}{c}\text { Gasoline, } \\
\text { Bu0 }\end{array}$ & 1 -butanol \\
\hline Formula & {$\left[\mathrm{kg} / \mathrm{dm}^{3}\right]$} & - & $\mathrm{C}_{4} \mathrm{H}_{10} \mathrm{O}$ \\
\hline Density & {$[\mathrm{kg}$ air $]$} & 14.737 & 0.810 \\
\hline Stoichiometric AF-ratio & {$[\mathrm{MJ} / \mathrm{kg}]$} & 42.7 & 11.10 \\
\hline Lower heating value & {$[\% \mathrm{~m}]$} & 1.70 & 21.62 \\
\hline $\mathrm{O}_{2}$ fraction & {$\left[{ }^{\circ} \mathrm{C}\right]$} & $38-175$ & $115-119$ \\
\hline Boiling range & & 95 & 99 \\
\hline Blending RON & & 87 & 84 \\
\hline Blending MON & {$\left[{ }^{\circ} \mathrm{C}\right]$} & 300 & 343 \\
\hline $\begin{array}{l}\text { Self-ignition tempera- } \\
\text { ture }\end{array}$ & & & $\left.3{ }^{\circ} \mathrm{C}\right]$ \\
\hline Flash point & {$\left[\mathrm{mPa}{ }^{*} \mathrm{~s}\right]$} & 0.83 & 2.9 \\
\hline Viscosity @ $40^{\circ} \mathrm{C}$ & & Bu15 & Bu30 \\
\hline \hline & {$\left[\mathrm{kg} / \mathrm{dm}^{3}\right]$} & 0.748 & 0.759 \\
\hline Density & {$[\mathrm{kg} \mathrm{air}]$} & 14.12 & 13.55 \\
\hline Stoichiometric AF-ratio & {$[\mathrm{MJ} / \mathrm{kg}]$} & 41.1 & 39.6 \\
\hline Lower heating value & {$\left[\%{ }_{\mathrm{m}}\right]$} & 3.50 & 8.08 \\
\hline $\mathrm{O}_{2}$ fraction & & \multicolumn{2}{|c|}{} \\
\hline
\end{tabular}

Table 2 presents the most important data of the fuels (according to the literature sources). It can be remarked that with increasing share of butanol the oxygen content of blend fuel increases and the heat value and stoichiometric air requirement decrease. 


\subsection{Lubricants}

In the present tests the lube oil was not changed and analyzed - the same oil was used for all tests.

\section{Test methods and instrumentation}

3.1. Chassis dynamometer and standard test equipment

- roller dynamometer: Schenk 500 GS 60

- driver conductor system: Tornado, version 3.3.

- CVS dilution system: Horiba CVS-9500T with Roots blower

- air conditioning in the hall automatic (intake- and dilution air)

The driving resistances of the test bench were set according to the legal prescription.

\subsection{Test equipment for regulated exhaust gas emissions}

This equipment fulfils the requirements of the Swiss and European exhaust gas legislation.

- gaseous components:

exhaust gas measuring system Horiba MEXA-9400H

$\mathrm{CO}, \mathrm{CO}_{2}$ - infrared analysers (IR), HCIR, HCFID, $\mathrm{NO} / \mathrm{NO}_{\mathrm{X}}, \mathrm{CLA}$

The dilution ratio DF in the CVS-dilution tunnel is variable and can be controlled by means of the $\mathrm{CO}_{2}$-analysis.

\subsection{FTIR}

FTIR (Fourier Transform Infrared) Spectrometer (AVL Sesam) offers the possibility of simultaneous, time-resolved measurement of approx. 30 emission components - among others: $\mathrm{NO}, \mathrm{NO}_{2}, \mathrm{NO}_{\mathrm{x}}, \mathrm{NH}_{3}, \mathrm{~N}_{2} \mathrm{O}, \mathrm{HCN}, \mathrm{HNCO}, \mathrm{HCHO}$ and $\mathrm{MeCHO}$.

\subsection{Nanoparticle analysis}

The measurements of NP size distributions were conducted with different SMPS-systems, which enabled different ranges of size analysis:

SMPS: DMA TSI 3081 and CPC TSI 3772 (9.8-429 nm)

nSMPS: nDMA TSI 3085 and CPC TSI 3025 (3-64 nm).

For the dilution and sample preparation an ASET system from Matter Aerosol was used, Fig. 2 (ASET - aerosol sampling and evaporation tube). This system contains:

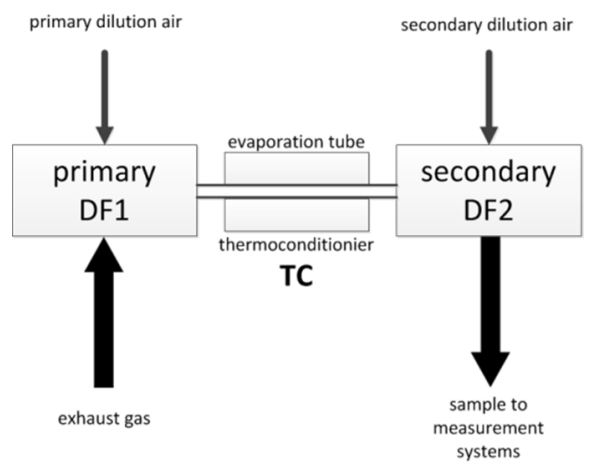

Fig. 2. Set-up of dilution stages and sample preparation for nanoparticle measurements

- Primary dilution air - MD19 tunable minidiluter (Matter Eng. MD19-2E)

- Secondary dilution air - dilution of the primary diluted and thermally conditioned measuring gas on the outlet of evaporative tube.
- Thermoconditioner (TC) - sample heating at $300^{\circ} \mathrm{C}$.

The measuring set-up on chassis dynamometer and the sampling positions for particle analytics are represented in Fig. 3.

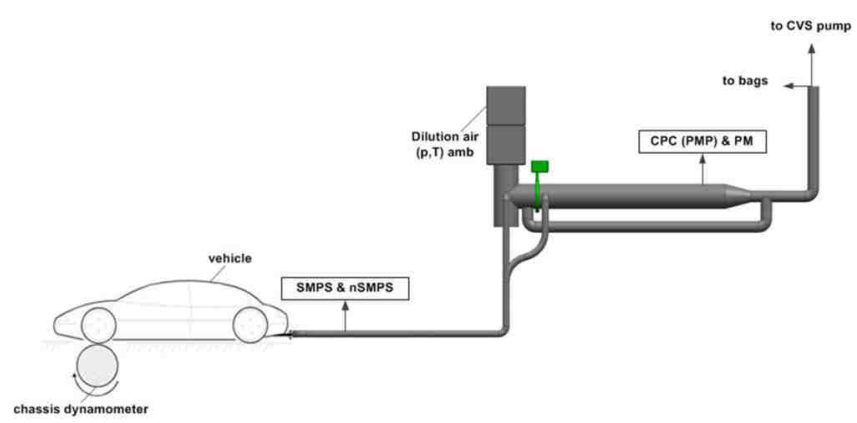

Fig. 3. Sampling of exhaust gas for analysis of particles

\section{Test procedures on chassis dynamometer}

The vehicles were tested on a chassis dynamometer in the dynamic driving cycles WLTC and at constant speeds in the steady state cycle SSC. SSC consists of 20 min steps at constant vehicle speeds $95,45 \mathrm{~km} / \mathrm{h}$ and idling, which are driven from the highest to the lowest speed. These vehicle speeds respond to the average speeds in parts of the WLTC. The test sequences with all fuels were identical: WLTC with cold start $\left(20-25^{\circ} \mathrm{C}\right), 10 \mathrm{~min}$ idling for bag evaluation, acceleration to $95 \mathrm{~km} / \mathrm{h}$ and continuation of the SSC.

In terms of the driving cycles an approach to find a homogenized world-wide driving cycle was finished with the development of the homogenized WLTP world-wide light duty test procedure. The WLTC (world-wide light duty test cycle) represents typical driving conditions around the world and is developed based on combination of collected in-use data and suitable weighting factors. This cycle has been used also in this study, Fig. 4. It represents different driving situation, like city, over-land and speed-way.

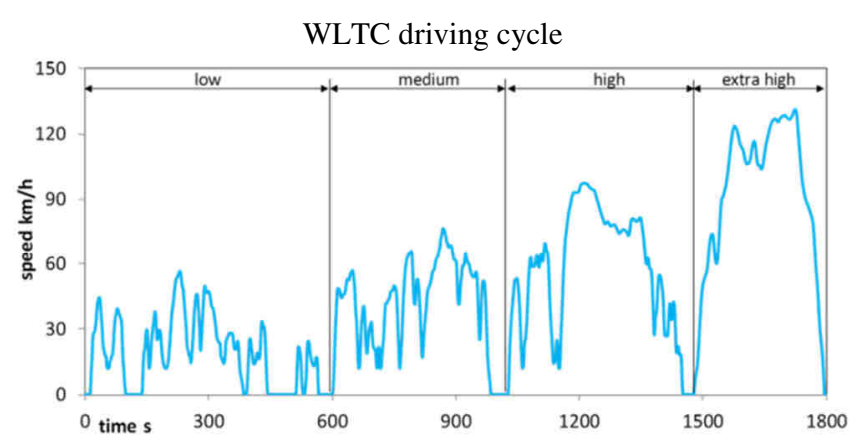

Fig. 4. WLTC driving cycle

\section{Results}

\subsection{Comparison of emissions of vehicles with older and with newer technology}

Regarding the comparison of emissions time-plots in WLTC (not represented here), it can be generally remarked for all three fuels (Bu0, Bu15 and Bu30): 
- with the older vehicle (R18) there are considerably higher emissions of $\mathrm{CO}$ and $\mathrm{HC}$ at cold start and there are higher and more frequent peaks of all components $\left(\mathrm{CO}, \mathrm{HC}\right.$ and $\left.\mathrm{NO}_{\mathrm{x}}\right)$ during the driving cycle,

- all non-legislated emissions: $\mathrm{NH}_{3}, \mathrm{HCHO}, \mathrm{MeCHO}$ and $\mathrm{N}_{2} \mathrm{O}$ are for $\mathrm{R} 18$ significantly higher.

Considering the integral average emissions in WLTC (whole cycle), Figs 5 and 6, these statements can be confirmed:

- $\quad$ higher CO- and HC-values with R18,

- $\quad$ with Bu15 CO is reduced more for V60, than for R18,

- with Bu30 CO for V60 stays at the level of Bu15, while for R18 it increased again to the original level of $\mathrm{Bu} 0$,

- $\quad$ HC for both vehicles is unchanged, or slightly reduced with $\mathrm{Bu} 15$, but it generally increases with Bu30,

- $\mathrm{NO}_{\mathrm{x}}$ is strongly increased by both BuXX fuels for the older vehicle (R18) and it is reduced for the newer ve-
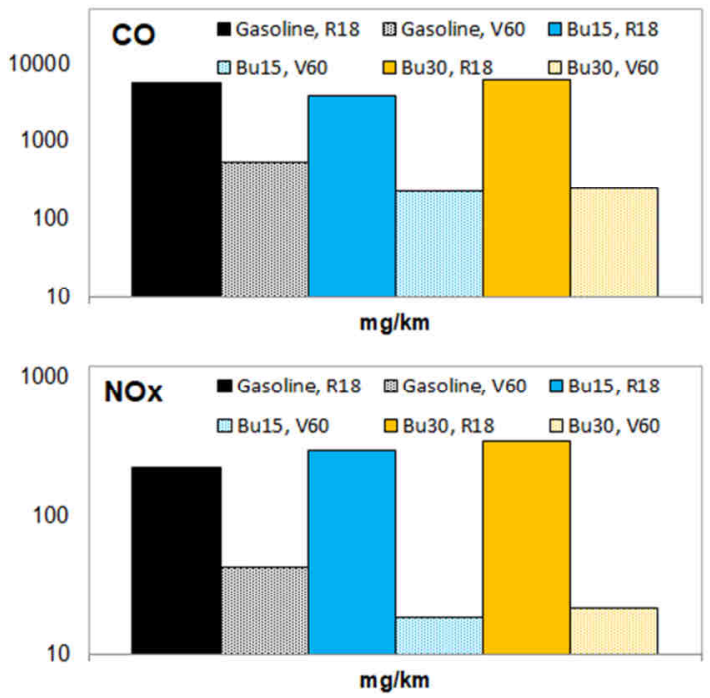

Fig. 5. Comparisons of emissions R18 vs V60 in WLTC cold with Bu0, Bu15 \& Bu30
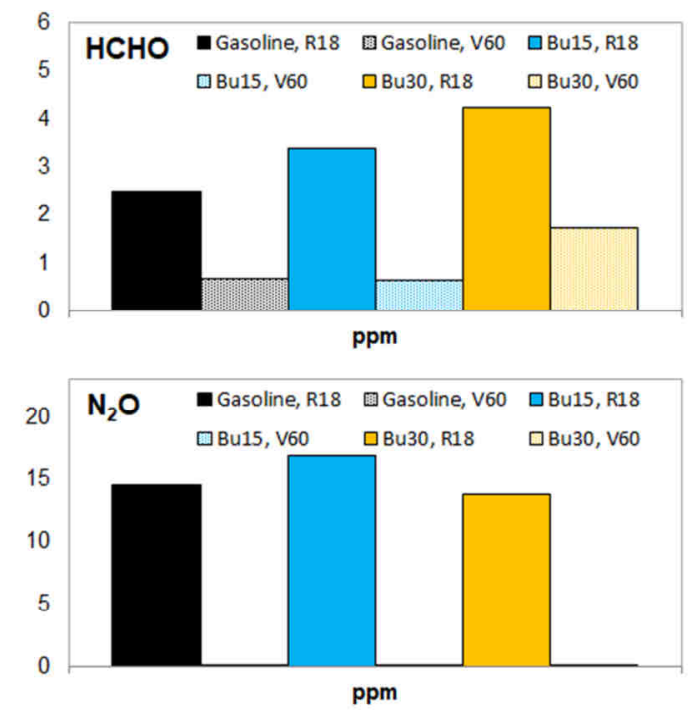

hicle (V60) - this is a sensitive indication of better functioning of the Lambda regulation of V60, with less "lean-excursions",

- the nanoparticle emission of V60 is significantly reduced with both BuXX-fuels; the PN emission of R18 is not influenced by the fuel,

- all non-legislated emissions: $\mathrm{NH}_{3}, \mathrm{HCHO}, \mathrm{MeCHO}$ and $\mathrm{N}_{2} \mathrm{O}$ are for $\mathrm{R} 18$ significantly higher,

- there is a tendency of increasing $\mathrm{HCHO}$ and $\mathrm{MeCHO}$ with increasing BuXX for both vehicles,

- with increasing BuXX there is an increase of $\mathrm{NH}_{3}$ for V60 and approximately no influence for R18.

One example of time-plots of non-legislated gaseous components, with both vehicles and with gasoline $(\mathrm{Bu} 0)$, is given in Fig. 7. It clearly demonstrates the advantages of the newer car (V60).

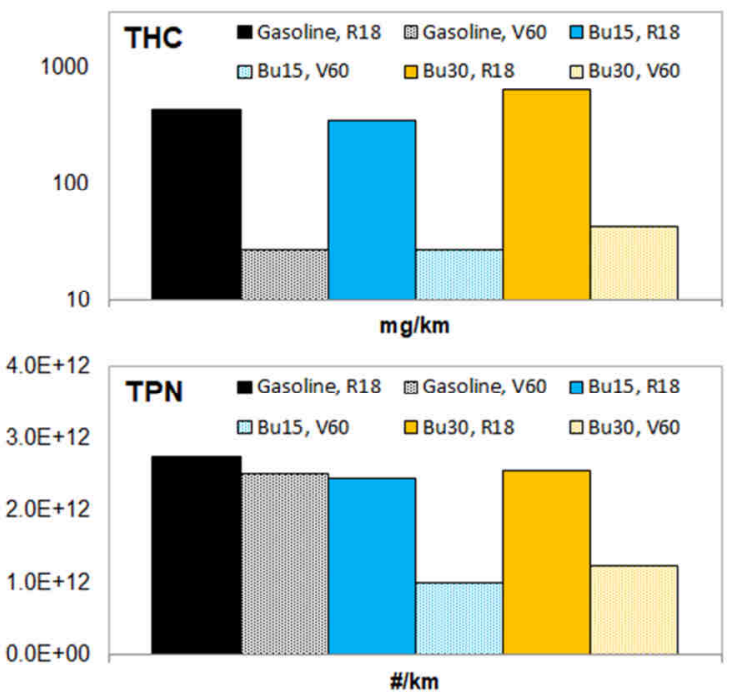

Fig. 6. Comparisons of non-legislated emissions in WLTC cold

Fig. 8 illustrates the relationships of emissions at 95 $\mathrm{km} / \mathrm{h}$ (in the 1 st step of SSC).
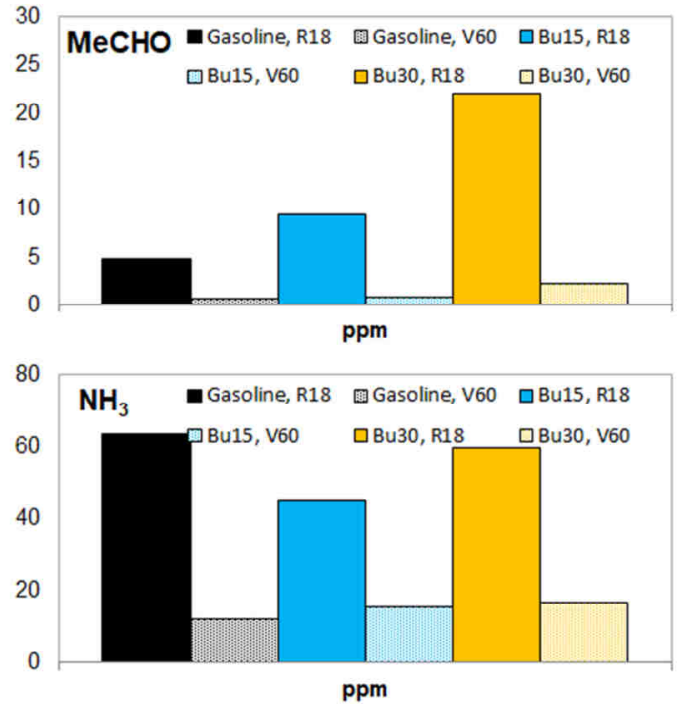
- in most cases there are higher CO-and HC-values for $\mathrm{R} 18$,

- with increasing Bu-content at $95 \mathrm{~km} / \mathrm{h}$ there is a strong increase of $\mathrm{NO}_{\mathrm{x}}$ for $\mathrm{R} 18$ and no influence on $\mathrm{NO}_{\mathrm{x}}$ for V60,

- the nanoparticle emission of V60 is significantly reduced with both BuXX-fuels; the PN emission of R18 is not influenced by the fuel,

- in most cases the higher values of $\mathrm{NH}_{3}, \mathrm{~N}_{2} \mathrm{O}$ and $\mathrm{MeCHO}$ are confirmed for R18.

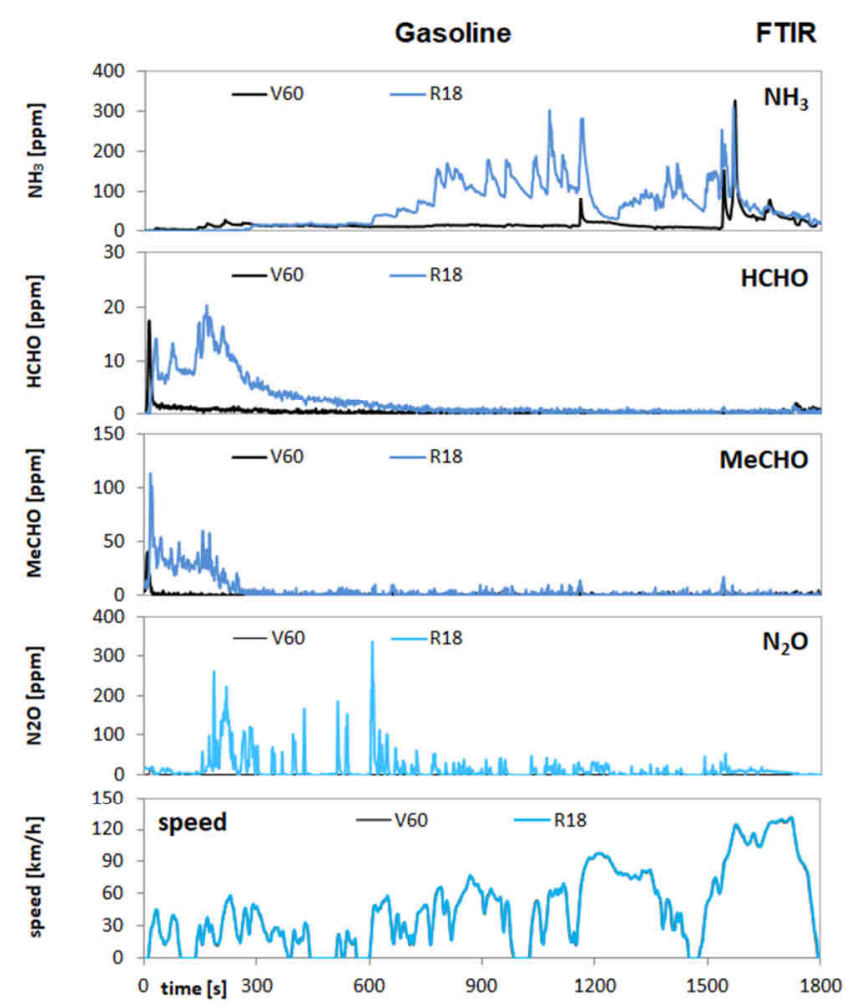

Fig. 7. Comparison of NH3-, HCHO-, MeCHO and N2O-emissions of two vehicles during the driving cycle WLTC cold

In the first step $(95 \mathrm{~km} / \mathrm{h})$ Volvo (V60) has with gasoline higher nanoparticle emissions (CPC), than Renault (R18). With Bu15 and Bu30 this is no more the case, since the NP are for V60 considerable reduced with BuXX.

After switching the operation to idling there is for R18 an increase of NP (CPC), because there are the highest PNemissions at idling for this vehicle. These NP consist in a large portion of unburned lube oil and it is not surprising that their number increases gradually with the cooling down the exhaust system and the catalyst (not represented here).

The highest NP-emissions at idling of R18, as well as their appearance mainly in the nuclei mode are documented in Fig. 9. The nanoSMPS offers at certain operating points, especially at $45 \mathrm{~km} / \mathrm{h}$, valuable supplementary information.

\subsection{Non-legislated emissions of both vehicles}

Figures $10 \& 11$ represent for both cars some nonlegislated components in the first part of the cycle with cold start and warm-up. The sequence of increased emission peaks with higher $\mathrm{Bu}$-content is clearly repetitive. There are considerable peak values with Bu30. For R18: HCHO up to $30 \mathrm{ppm}$ and $\mathrm{MeCHO}$ up to $950 \mathrm{ppm}$ and for V60: HCHO up to $60 \mathrm{ppm}$ and $\mathrm{MeCHO}$ up to $220 \mathrm{ppm}$. $\mathrm{N}_{2} \mathrm{O}$ emission peaks depend only few from the fuel variant. $\mathrm{NH}_{3}$-values are generally low after the cold start and they become higher in the hot last part of the cycle.
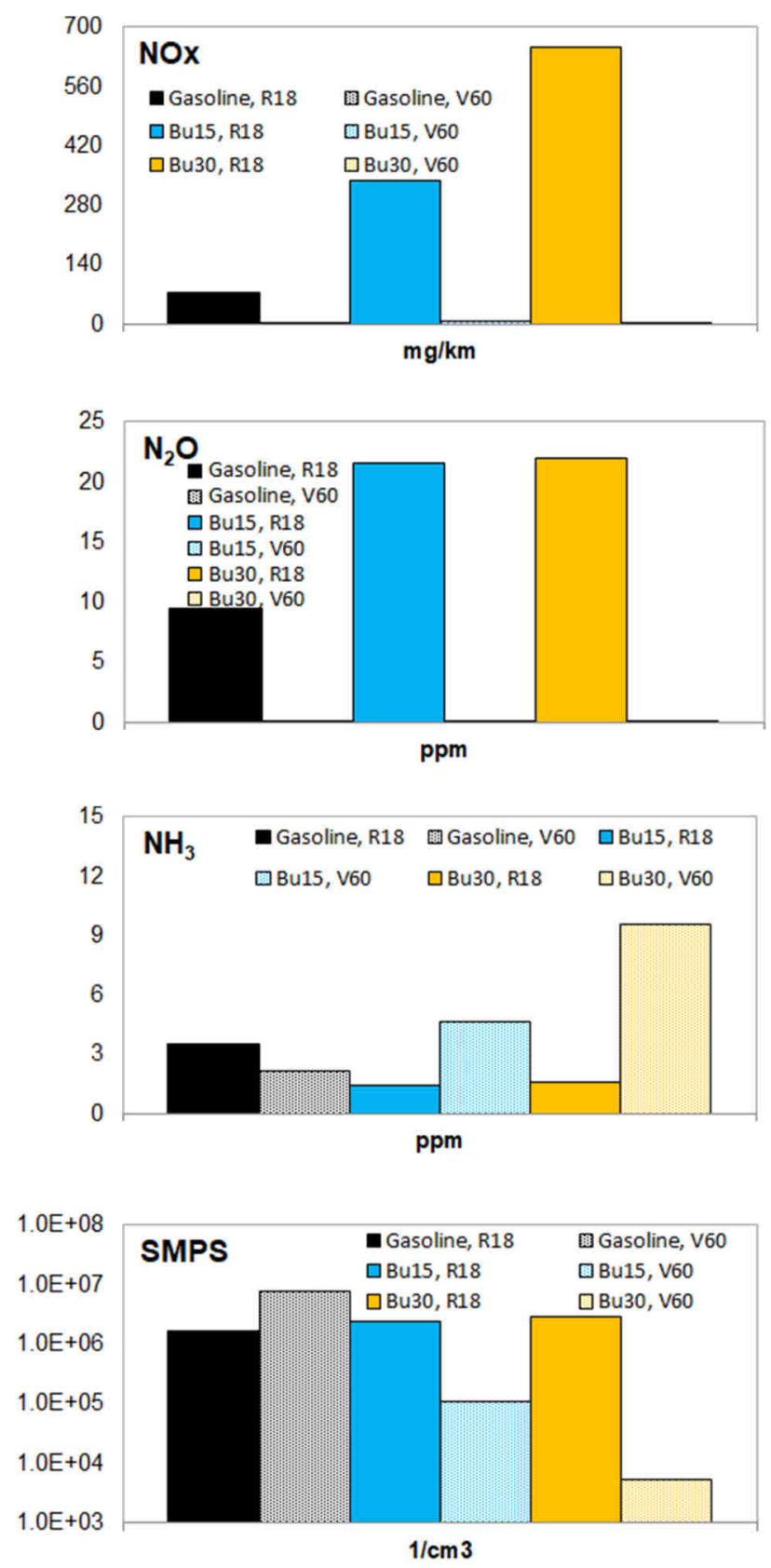

Fig. 8. Comparison of exhaust emissions of two vehicles at $95 \mathrm{~km} / \mathrm{h}$ with different fuels

Figures $12 \& 13$ offer a consideration of SMPS particle size distributions for both vehicles, with three fuels and in all steps of the SSC.

For R18, the particle size distributions with SMPS (and with nSMPS) show principally higher PN-values with higher butanol content. At $45 \mathrm{~km} / \mathrm{h}$ there is a major part of nanoparticles in the smallest sizes, below the measuring range of SMPS. The highest PN-concentration are reached at idling. This vehicle is known to produce excessive NPemissions in nuclei mode, which originate from the higher lube oil consumption. 


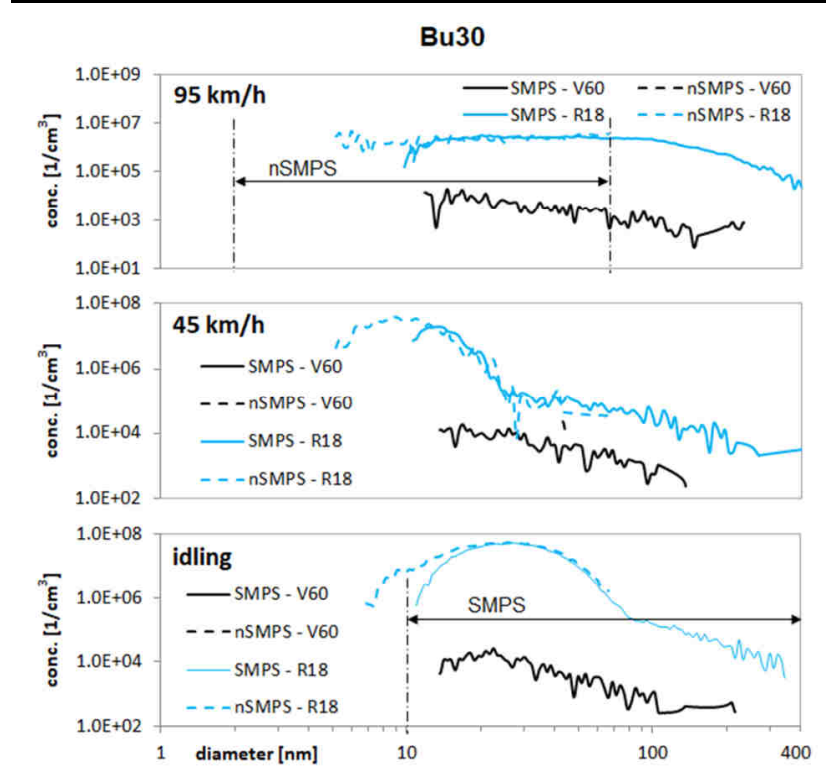

Fig. 9. Particle Size Distribution (PSD) during the SSC cycle. Comparison SMPS - nSMPS of two vehicles

\section{Renault 18, FTIR}

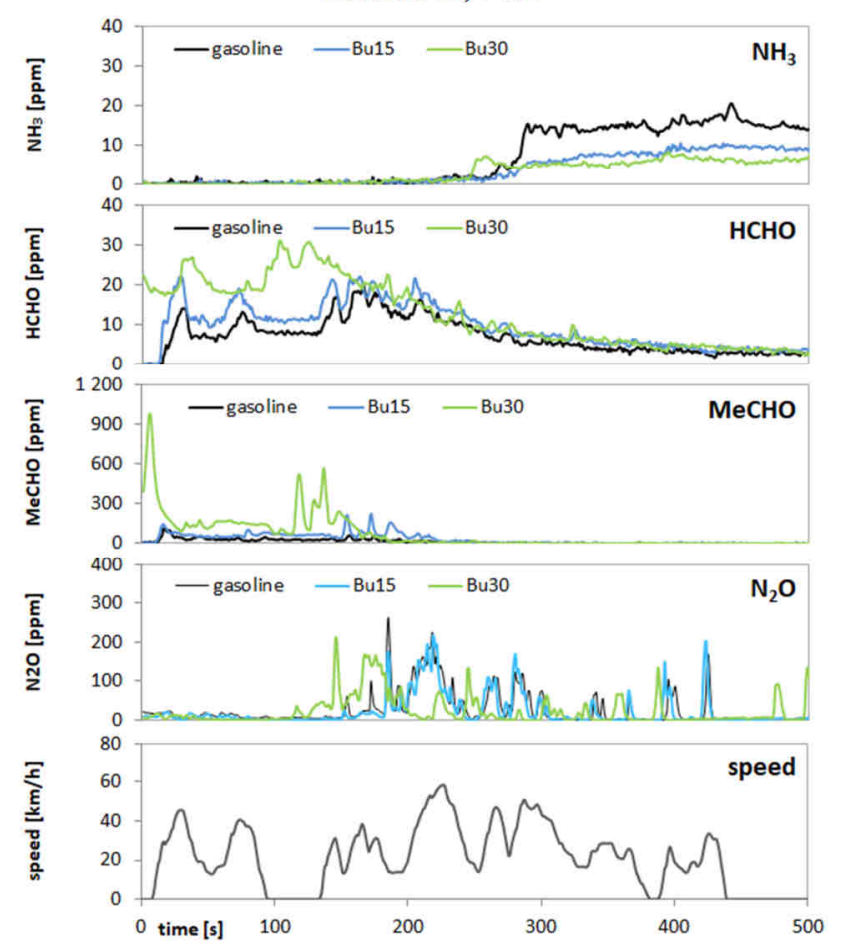

Fig. 10. Comparison of $\mathrm{NH}_{3}-$, $\mathrm{HCHO}-, \mathrm{MeCHO}-\& \mathrm{~N}_{2} \mathrm{O}$-emissions in the first part of WLTC cold with different fuels

For V60, there is an inverse influence of Bu-blends: there is a clear lowering of particle number $(\mathrm{PN})$ with increasing BuXX. At idling, generally the lowest PN counts concentrations are resulting.

From the comparisons in this section, it can be concluded that the different engines' ages and technology (different mixtures' preparations MPI/DI, combustion, lube oil consumption and exhaust aftertreatment) have a significant impact on the emissions and especially on the emissions at cold start.

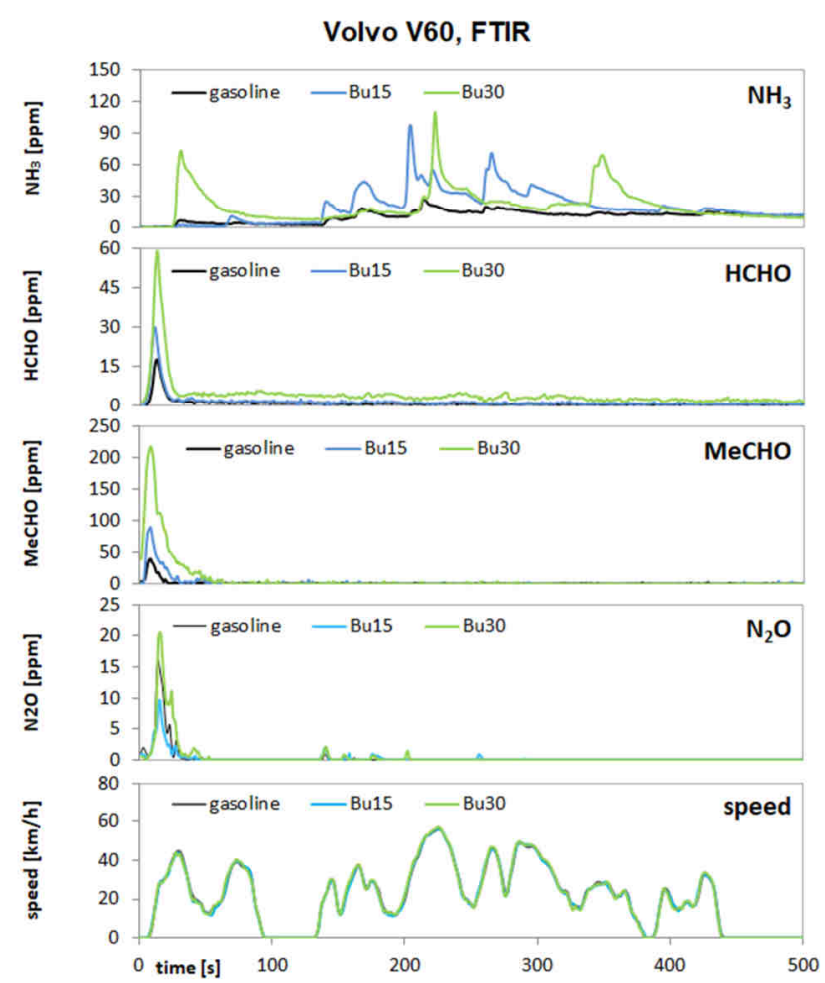

Fig. 11. Comparison of $\mathrm{NH}_{3}-$, $\mathrm{HCHO}-, \mathrm{MeCHO}-\& \mathrm{~N}_{2} \mathrm{O}-$ emissions in the first part of WLTC cold with different fuels

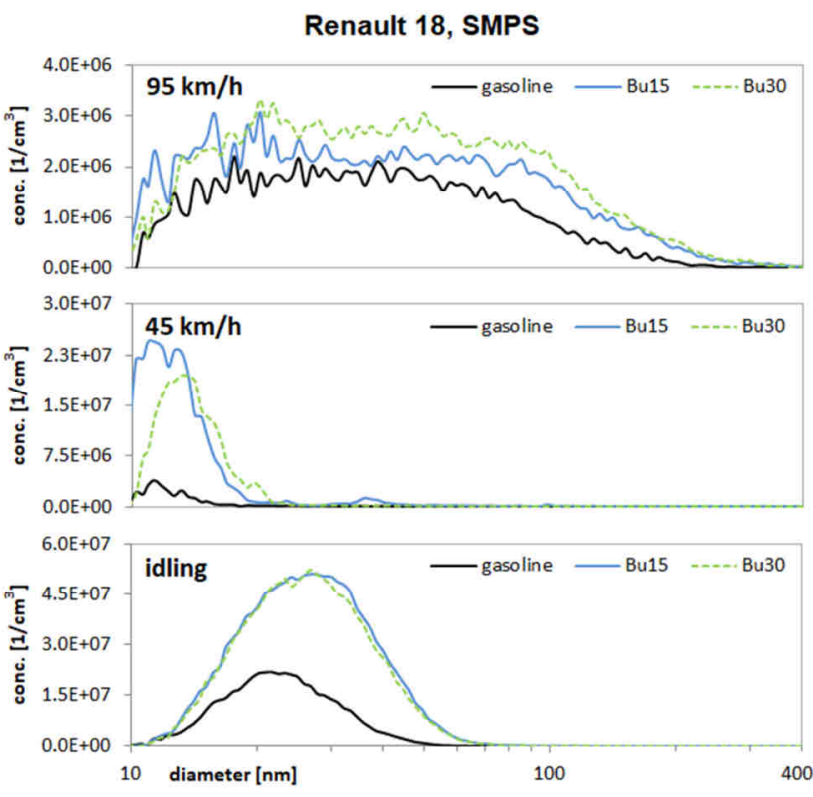

Fig. 12. Comparison of the Particle Size Distribution (PSD) during the driving cycle SSC with different fuels

\subsection{Cold start}

Repetitive cold start tests were performed with Volvo V60 and with Bu0/Bu15/Bu30. For cold starts (CS), two ranges of start temperature were considered: summer cold start (20 to $25^{\circ} \mathrm{C}$, conditioning in the test hall), or mild winter cold start $\left(-2\right.$ to $4^{\circ} \mathrm{C}$, conditioning outside in the cold weather period). For simplification of titles and descriptions these temperature ranges will be designed, as $20^{\circ} \mathrm{C}$ and $0{ }^{\circ} \mathrm{C}$. 


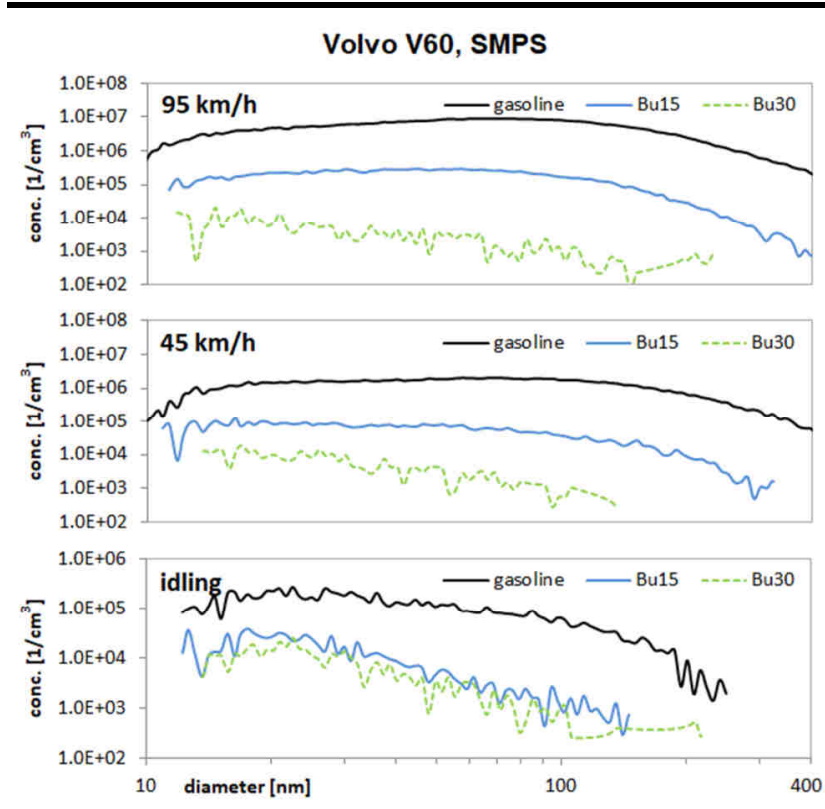

Fig. 13. Comparison of the Particle Size Distribution (PSD) during the driving cycle SSC with different fuels

In the preliminary tests with gasoline two variants of cold start were investigated:

a. cold start at idling (without chassis dynamometer),

b. cold start with acceleration to $20 \mathrm{~km} / \mathrm{h}$ and $\mathrm{v}=$ const $=$ $20 \mathrm{~km}$ on the chassis dynamometer, the braking resistances were set according to legal prescriptions and they responded to the horizontal road.

It was stated after this test period, that the CS on chassis dynamometer (with $20 \mathrm{~km} / \mathrm{h}$ ) does not bring any further information potentials and further research was generally limited to the CS at idling. Vehicle, which was conditioned outside for the mild winter CS was pushed in the test hall, attached to the measuring systems, started and operated in the conditions of the hall (intake air $20-25^{\circ} \mathrm{C}$ ). After the test, the vehicle was conditioned by driving a NEDC on the chassis dynamometer.

Fig. 14 shows some non-legislated gaseous components, comparing $\mathrm{Bu} 0 / \mathrm{Bu} 15 / \mathrm{Bu} 30$ in two temperature domains of the $\mathrm{CS}: 0^{\circ} \mathrm{C}$ and $20^{\circ} \mathrm{C}$. With higher Bu-content the peaks of formaldehyde $\mathrm{HCHO}$ and of acetaldehyde $\mathrm{MeCHO}$ increase. Starting with a lower temperature, these peak-values are higher and can attain for MeCHO $250 \mathrm{ppm}$. The ammonia $\mathrm{NH}_{3}$ concentrations are at cold start (CS) near to zero and they increase slightly after engine warms up. Nevertheless, there is for $\mathrm{NH}_{3}$ no correlation with fuel quality.

Fig. 15 compares the nanoparticle emissions with the fuels $\mathrm{Bu} 0 / \mathrm{Bu} 15 / \mathrm{Bu} 30$ at $\mathrm{CS}$ in both temperature ranges $0^{\circ} \mathrm{C}$ $\& 20^{\circ} \mathrm{C}$. CPC (condensation particle counter) measures the particle numbers of all particle sizes according to the PMPguidelines. SMPS (scanning mobility particle sizer) measures the particle numbers in function of their size.

The SMPS-particle size distributions were taken in the successive parts of the warm-up period: (1) 0-120 s; (2) 120-300 s and (3) 300-600 s.
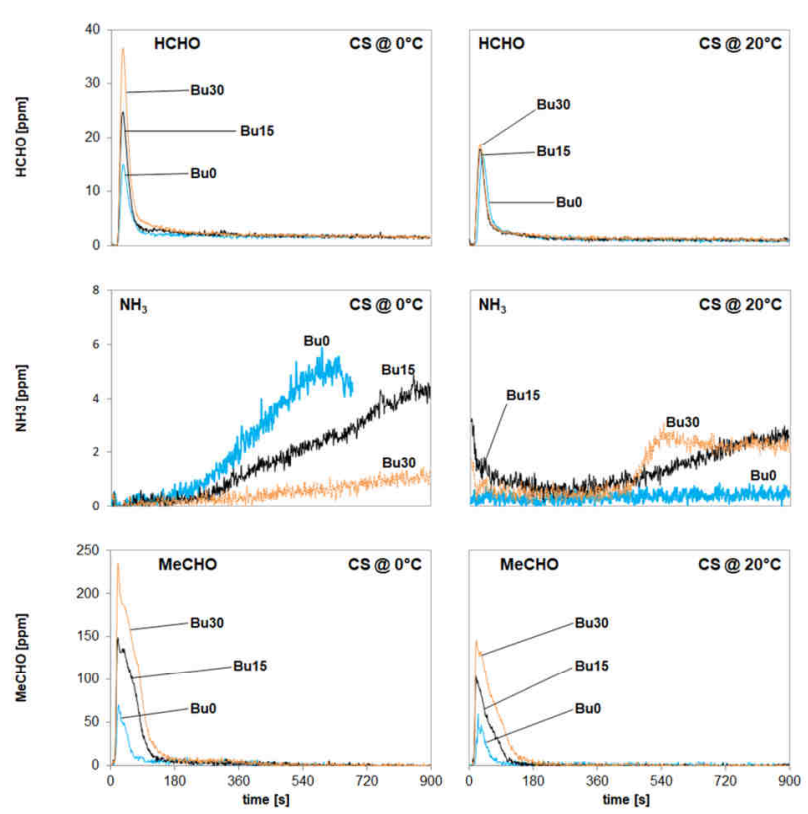

Fig. 14. Comparison of the non-legislated gaseous emissions during cold start at idling with different fuels, measured with FTIR at tailpipe
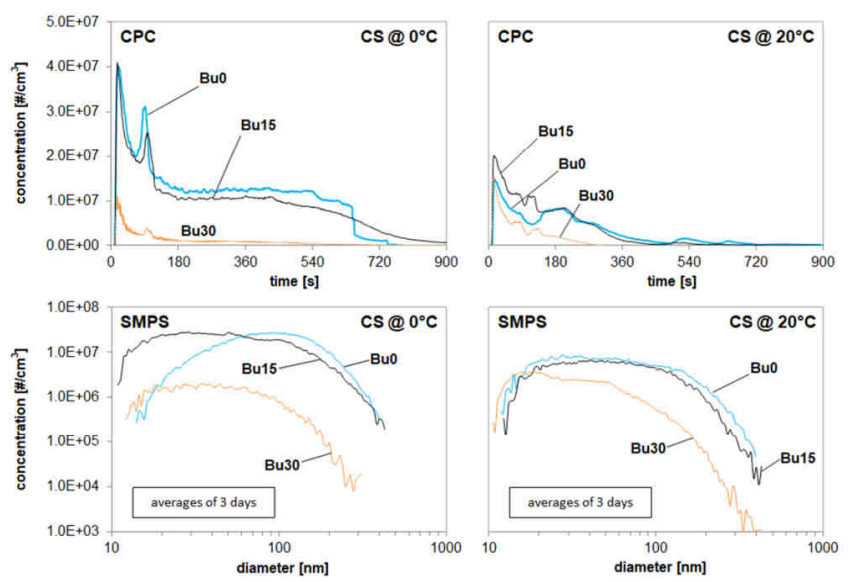

Fig. 15. Comparison of the particles counts during cold start at idling with different fuels, measured with both systems at tailpipe

The successive SMPS-scans of each CS-attempt (not represented here) showed clearly the lowest PC-level of the latest sample. The $1^{\text {st }}$ sample was well repeatable and the PSD's in Fig. 4 are averages from three cold starts of the $1^{\text {st }}$ scan (in the period 0-120 s).

The CPC-signals at $0^{\circ} \mathrm{C}$ have a second peak after approximately $2 \mathrm{~min}$. This is visible particularly with gasoline (E0). This peak is a repeatable event, it can also be found in other emission courses (like $\mathrm{N}_{2} \mathrm{O}$ ) and it is attributed to the changes introduced by the engine ECU in function of temperature, like possibly catalyst heating, switching of internal EGR by vario cams, or heat management.

The most important information of Fig. 15 is that Bu15 emits similar level of particle counts concentration, like $\mathrm{Bu} 0$, while $\mathrm{B} 30$ reduces clearly the PN emissions. Bu15 has similar oxygen content like E10. Nevertheless, it was found that $\mathrm{Bu} 15$ produces significantly higher peaks of $\mathrm{MeCHO}$ and $\mathrm{HCHO}$ at cold start than E10 [3]. 


\section{Conclusions} R18:

The elaborated results allow following observations for

- At cold start and warm-up all three investigated fuels produce increased CO-, HC- and NP-values in similar way.

- The emissions of $\mathrm{HCHO}$ and $\mathrm{MeCHO}$ at cold start increase in the sequence of increasing butanol content.

- In the "high" and "extra high" parts of WLTC there are the highest $\mathrm{NH}_{3}$ peaks, which coincide with the strongest acceleration events in the cycle.

- $\quad$ Regarding the average emission values in WLTC cold: with increasing butanol content $(\mathrm{BuXX})$ there is a clear tendency of increasing the emissions of: $\mathrm{NO}_{\mathrm{x}}, \mathrm{HCHO}$, $\mathrm{MeCHO}$ and ETOH. The average emissions of $\mathrm{N}_{2} \mathrm{O}$ and $\mathrm{NH}_{3}$ are independent on the BuXX.

- At steady state operation (in SSC) with increasing butanol content there are:

- higher $\mathrm{NO}_{\mathrm{x}}$-values at the highest speed $(95 \mathrm{~km} / \mathrm{h})$, - higher PN-values at all operating conditions.

$>$ With higher butanol content, the lambda regulation of this vehicle has difficulty to compensate the higher oxygen content of the fuel. As a result, there is a leaner operation and lower $\mathrm{NO}_{\mathrm{x}}$-conversion in the TWC.

$>$ Higher butanol content interferes more with the lube oil and tendentiously increases the nanoparticles counts.

$>$ Higher butanol content also creates favourable conditions to produce more formaldehyde (HCHO) and acetaldehyde (MeCHO) at cold start.

With B30 the excessive leaning was remarkable as a less powerful load responses and worse driveability. B30 is regarded as a maximum of butanol content to be recommended for this vehicle.

For Volvo V60 and for transient operation in WLTC can be remarked:

- With increasing portion of butanol in fuel (BuXX) there are increasing peak values of $\mathrm{HC}, \mathrm{HCHO}, \mathrm{MeCHO}$, ETOH and $\mathrm{N}_{2} \mathrm{O}$ at cold start.

- During and after the acceleration events in the highest part of the cycle there are emission peaks of some components, but they cannot be attributed to a specific bucontent (BuXX).

- The comparison of average emission values in WLTC, confirms the lower CO- and lower PN-values with $\mathrm{BuXX}$, while it is difficult to notice the difference between Bu15 and Bu30.
- The average of FTIR-values confirms the higher values of: $\mathrm{HCHO}, \mathrm{MeCHO}$ and $\mathrm{NH}_{3}$ with BuXX.

- There is a clear lowering of particle number (PN) with increasing BuXX.

\section{Comparison R18-V60 in WLTC}

- Higher CO- and HC-values with R18 and no clear influence of fuel on these emissions.

- HC for both vehicles is unchanged, or slightly reduced with Bu15, but it generally increases with Bu30.

- $\mathrm{NO}_{\mathrm{x}}$ is strongly increased by both BuXX fuels for the older vehicle (R18) and it is reduced for the newer vehicle (V60) - this is a sensitive indication of better functioning of the lambda regulation of V60, with less "leanexcursions".

- The nanoparticle emission of V60 is significantly reduced with both BuXX-fuels; the PN emission of R18 is not influenced by the fuel.

- All non-legislated emissions: $\mathrm{NH}_{3}, \mathrm{HCHO}, \mathrm{MeCHO}$ and $\mathrm{N}_{2} \mathrm{O}$ are for R18 significantly higher.

- There is a tendency of increasing $\mathrm{HCHO}$ and $\mathrm{MeCHO}$ with increasing BuXX for both vehicles.

- With increasing BuXX there is an increase of $\mathrm{NH}_{3}$ for V60 and approximately no influence for R18.

For cold start tests with Volvo V60 can be concluded:

- With increasing butanol content $(\mathrm{Bu} 0 / \mathrm{Bu} 15 / \mathrm{Bu} 30)$ the emissions at cold start are influenced in following way:

o Higher peaks of acetaldehyde (MeCHO) at start,

o Higher peaks of formaldehyde (HCHO) at start,

o The nanoparticles with Bu15 have similar level as with Bu0 (both CPC and SMPS), with Bu30 they are approximately 1 order of magnitude lower.

- The higher temperature of the cold start generally lowers the emission peaks.

It is important to mention that the original plans of this project part were to test the cold start with Bu85. This was also tried in both temperature domains $\left(0^{\circ} \mathrm{C} \& 20^{\circ} \mathrm{C}\right)$ but without success. The start and the operation were not possible with this FFV. Butanol has a higher boiling point, than ethanol and therefore the quality of mixture preparation (part of evaporated fuel) with butanol is worse. The investigated vehicle (FFV) is developed for ethanol and cannot work adequately with higher butanol contents.

\section{Acknowledgements}

The authors want to express their gratitude to the institutions, which financially supported these research activities: Swiss Federal Office of Energy (BfE), Swiss Federal Office of Environment (BAFU) and Swiss Oil Association (EV).

\section{Nomenclature}

AFHB Abgasprüfstelle FH Biel, CH

ASET Aerosol Sampling and Evaporation Tube

ASTRA Amt für Strassen $(\mathrm{CH})$

BAFU Bundesamt für Umwelt, (Swiss EPA)

BfE Bundesamt für Energie

$\mathrm{Bu}$ butanol

BuXX butanol content XX

CLA chemiluminescent analyzer

CLD chemiluminescent detector
$\mathrm{CO}$

$\mathrm{CO}_{2}$

$\mathrm{CPC}$

CS

CVS

DF

DI

DMA differential mobility analyzer

ECU electronic control unit 


\begin{tabular}{llll}
\hline EV & Erdölvereinigung & $\mathrm{N}_{2} \mathrm{O}$ & nitrous oxide \\
FFV & flex fuel vehicle & $\mathrm{N}_{2}$ & nitrogene \\
FID & flame ionisation detector & $\mathrm{NO}_{x}$ & nitric oxides \\
FTIR & Fourier Transform Infrared analyzer & $\mathrm{NP}$ & nanoparticles $<999 \mathrm{~nm}$ \\
GasBut & gasoline buthanol project & $\mathrm{PC}$ & particle counts (integrated) \\
$\mathrm{HC}$ & unburned hydrocarbons & $\mathrm{PN}$ & particle numbers \\
$\mathrm{HCHO}$ & formaldehyde & $\mathrm{PSD}$ & particle size distribution \\
$\mathrm{HCN}$ & hydrogen cyanide & $\mathrm{R} 18$ & Renault 18 \\
$\mathrm{HNCO}$ & isocyanic acid & $\mathrm{SMPS}$ & scanning mobility particle sizer \\
$\mathrm{MD}$ & minidiluter & $\mathrm{TC}$ & thermoconditioner \\
$\mathrm{MeCHO}$ & acetaldehyde & $\mathrm{TWC}$ & three way catalyst \\
$\mathrm{NEDC}$ & New European Driving Cycle (ECE + EUDC) & V60 & Volvo V60 \\
$\mathrm{NH}_{3}$ & ammonia & WLTC & worldwide harmonized light duty test cycle \\
$\mathrm{NO}^{2}$ nitrogen monoxide & WLTP & worldwide harmonized light duty test procedure \\
$\mathrm{NO}_{2}$ & nitrogen dioxide & $3 \mathrm{WC}$ & three way catalyst
\end{tabular}

\section{Bibliography}

[1] BRASSAT, A., THEWES, M., MÜTHER M. et al. Massgeschneiderte Kraftstoffe aus Biomasse für Ottomotoren. MTZ. 2011, 12, 988.

[2] MARCHITTO, L., MAZZEI, A., MEROLA, S.S. et al. Optical investigations of combustion process in SI and CI engines fuelled with butanol blends. TAE Technische Akademie Esslingen, $9^{\text {th }}$ International Colloquium "Fuels", Jan. 15-17, 2013.

[3] IRIMESCU, A., TORNATORE, C., MEROLA, S.S. et al. Integrated diagnostics for combustion investigation in a DISI engine fueled with butanol and gasoline at different load settings. TAE Technische Akademie Esslingen, 10th International Colloquium „Fuels“, Stuttgart/Ostfildern, January 2015, p. 117.

[4] TORNATORE C., MARCHITTO L., VALENTINO G. et al. Optical diagnostics of the combustion process in a PFI SI boosted engine fueled with butanol-gasoline blend. Energy. 2012, 45(1), 277-287, doi: 10.1016/j.energy.2012.03.006.

[5] MEROLA, S., TORNATORE, C., MARCHITTO, L. et al. Experimental investigations of butanol-gasoline blends effects on the combustion process in a SI engine. International Journal of Energy and Environmental Engineering, 2012, doi: 10.1186/2251-6832-3-6.

[6] SZWAJA S., NABER J.D. Combustion of n-butanol in a spark-ignition IC engine. Fuel. 2010, 89(7), 1573-1582, doi:10.1016/j.fuel.2009.08.043.

[7] GU, X., HUANG, Z., CAI, J. et al. Emission characteristics of a spark-ignition engine fuelled with gasoline-n-butanol blends in combination with EGR. Fuel. 2012, 93, 611-617, doi:10.1016/j.fuel.2011.11.040.

\author{
Jan Czerwinski, Prof. DEng. - Professor in the \\ University of Applied Sciences, Biel-Bienne, \\ Switzerland. \\ e-mail: Jan.Czerwinski@bfh.ch
}

Pierre Comte, Dipl.-HTL-Ing. - University of Applied Sciences, Biel-Bienne, Switzerland.

e-mail: Pierre.Comte@bfh.ch
[8] DERNOTTE, J., MOUNAIM-ROUSSELlE, C., HALTER, F. et al. Evaluation of butanol-gasoline blends in a port fuelinjection, spark-ignition engine. Oil Gas Sci Technol - Rev IFP, 2010, 65, 45-51, doi: 10.2516/ogst/2009034.

[9] VOJTISEK-LOM, M., PECHOUT, M., MAZAC, M. Realworld on-road exhaust emissions from an ordinary gasoline car operated on E85 and on butanol-gasoline blend. SAE Technical Paper 2013-24-0102.

[10] CHAN, T.W., MELOCHE, E., KUBSH, J. et al. Impact of ambient temperature on gaseous and particle emissions from a direct injection gasoline vehicle and its implications on particle filtration. SAE Technical Paper 2013-01-0527.

[11] SONNTAG, D.B., BAILEY, C.R., FULPER, C.R. et al. Contribution of lubricating oil to particulate matter emissions from light-duty gasoline vehicles in Kansas City. Environment Science \& Technology, 27. Febr. 2012.

[12] PORTER, S. Particle number emissions of gasoline hybrid electric vehicle. MTZ. 2012, 4.

[13] HEEB, N., FORSS, A-M., BRÜHLMANN, S. et al. Threeway catalyst-induced formation of ammonia - velocity- and acceleration-dependent emission factors. Atmospheric Environment. 2006, 40, 5986-5997.

[14] HEEB, N., SAXER, C., FORSS, A.-M. et al. Trends of NO-, $\mathrm{NO}_{2^{-}}$, and $\mathrm{NH}_{3}$-emissions from gasoline-fueled Euro-3- to Euro-4-passenger cars. Atmospheric Environment. 2008, 42, 2543-2554.

[15] CZERWINSKI, J., COMTE, P., STEPIEN, Z. et al. Effects of ethanol blend fuels E10 \& E85 on the non-legislated emissions of a flex fuel passenger car. SAE Technical Paper 2016-01-0977.

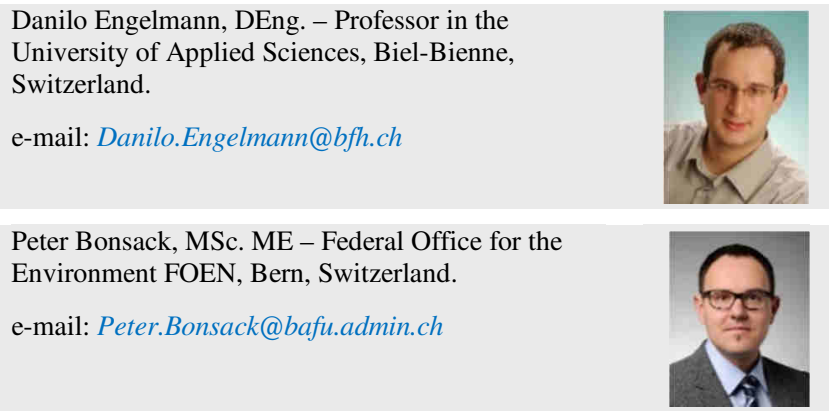

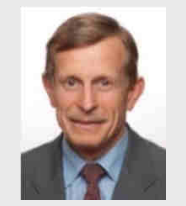

(n)

